ISSUES IN PUBLIC HEALTH

\title{
Mortality analysis of people with severe mental illness transferred from long-stay hospital to alternative care in the Life Esidimeni tragedy
}

\author{
L J Robertson, ${ }^{1}$ FC Psych (SA), MMed; M W Makgoba, ${ }^{2}$ D Phil (Oxon), FRCP (Lond), FRS (SA), OMS \\ ${ }^{1}$ Department of Psychiatry, Faculty of Health Sciences, University of the Witwatersrand, Johannesburg, South Africa \\ ${ }^{2}$ Health Ombud, Republic of South Africa
}

Corresponding author: LJ Robertson (lesley.robertson@wits.ac.za)

\begin{abstract}
A mortality analysis of the Life Esidimeni tragedy was precluded during the investigation by the Health Ombud by the lack of data integrity. Information on the mental healthcare users (MHCUs) transferred out of Life Esidimeni hospitals between October 2015 and June 2016 was subsequently collected by the Gauteng Department of Health, permitting statistical analysis. Survival rates were calculated according to gender and transfer destination and adjusted for patient age. Mortality was compared with that of the general population for the calendar year of 2016. Of the 1442 MHCUs, 15\% were transferred to specialised psychiatric hospitals and 85\% to a rehabilitation centre or non-governmental residential facility. By the end of August 2017, 9\% $(n=131)$ of the cohort had died. Significant predictors of survival were younger age $(p<0.0001)$ and transfer to a psychiatric institution $(p=0.004)$. The age-adjusted death rate was $63 / 1000$ and the overall standardised mortality ratio (SMR) was 4.9 (95\% confidence interval (CI) 3.92 - 5.80), with an SMR of 3.9 (95\% CI 2.95 - 4.86) for men and 6.3 (95\% CI 4.22 - 8.38) for women. The excess deaths are therefore quantified, and the high-risk environment of the rehabilitation centre and residential facilities confirmed. High mortality among MHCUs is unlikely to be confined to the Life Esidimeni tragedy; monitoring of preventable deaths in this vulnerable population is recommended.
\end{abstract}

S Afr Med J 2018;108(10):813-817. DOI:10.7196/SAMJ.2018.v108i10.13269

The association between severe mental illness and mortality is not commonly recognised. ${ }^{[1]}$ Nonetheless, it was the deaths of 36 mental healthcare users (MHCUs) in September 2016 that caused a public outcry in Gauteng Province and the Minister of Health to request the Office of the Health Ombud (the Ombud) to investigate the circumstances surrounding the deaths. ${ }^{[2]}$ These circumstances are described in detail in the Ombud's report of the investigation, ${ }^{[2]}$ have been examined in the Life Esidimeni Arbitration, and continue to be explored in the media ${ }^{[3]}$ and in academic discourse ${ }^{[4,5]}$ However, the mortality analysis has not yet been made public.

The events began in October 2015, when the Gauteng Department of Health (GDoH) announced its decision to terminate a 40-year contract with Life Healthcare Esidimeni (LE) for the provision of medium- to long-stay mental hospital care. ${ }^{[6]}$ Affordability and the need to re-prioritise the budget were the given rationale. There had been no complaints regarding the quality of healthcare at the LE institutions, but the GDoH stated that the decision would allow patients to be treated closer to their homes and reintegrated into their communities, consistent with the requirements of the Mental Health Care Act No. 17 of 2002 (MHCA). ${ }^{[7]}$ These minimum requirements were never met.

By 30 June 2016, all MHCUs at the LE hospitals had either been discharged home or transferred to alternative care facilities. These facilities comprised two specialised psychiatric hospitals, the Cullinan Care and Rehabilitation Centre (CCRC) for the intellectually disabled, and at least 27 non-governmental residential homes (NGOs). Preparatory arrangements included the renovation and staffing of wards in the psychiatric hospitals, employment of additional nursing staff at the CCRC, and the recruitment of individuals to run NGOs, which were either in old hospital premises or residential houses. Over a thousand MHCUs were transferred during the last 2 months of the process, and many of the patients initially placed at the CCRC or an NGO were transferred a second or third time before being settled.

A lack of data integrity during the transfer process was both an important finding of the investigation and a limitation. When the Ombud's report ${ }^{[2]}$ was released on 1 February 2017, the whereabouts of all the MHCUs and how many had died were still unknown. In addition, no statistical analysis could be performed. On p. 42 of his report, the Ombud quotes the Statistician-General as stating:

'This investigation highlights the importance of proper administrative record management across all institutions. The presence of such is an enabler to comprehensive analysis and monitoring of issues. In the present case, the data gaps that resulted as a consequence of inadequate record keeping have limited the kind of analysis that could have been made and thus enabled comparison of mortality levels across time and between institutions.

The Ombud therefore recommended that the GDoH develop information systems and patient registers. He also recommended that all the transferred MHCUs be identified and relocated to suitable health establishments. A data verification team was established in Gauteng to fulfil these requirements.

\section{Objectives}

This article presents an analysis of the information collected by the data verification team. The objective was to describe the mortality 
among the cohort of patients who were transferred out of LE between October 2015 and June 2016. The purpose was to build on the work of the expert panel and to support the Ombud's final report on the investigation. We sought to answer two questions: $(i)$ what was the difference in mortality rate between those transferred to an $\mathrm{NGO} /$ the CCRC and those transferred to a hospital? and (ii) what was the difference between the mortality rate of this cohort and that in the general population for 2016 ?

\section{Methods}

\section{Study population}

The study population comprised those MHCUs at LE who were transferred to an alternative care facility between October 2015 and June 2016. The entire study population had severe mental illness and had been admitted to LE under the MHCA as assisted MHCUs, according to the prevailing agreement between the GDoH and LE. The study period was from October 2015 to August 2017.

\section{Data collection}

The data were collected by the data verification team using multiple sources. These included LE, the GDoH, the task team that supervised the relocation of patients back into a hospital environment, the Department of Home Affairs, the South African Social Security Agency and the Office of the Health Ombud. The data were cleaned by the authors in consultation with the data verification team, LE, the psychiatric hospitals and records from the initial investigation. One patient was removed from the cohort as a duplicate entry and one was removed from the list of deaths because he had been transferred before the study period. Specific psychiatric diagnoses and causes of death were not available. However, according to the GDoH, there were no deaths due to trauma and only one suspected suicide.

\section{Measures of mortality}

The preliminary Life Table of the general population for 2016 was provided by the Statistician-General for the assessment of mortality. We used two measures: the age-adjusted death rate and the standardised mortality ratio (SMR) ${ }^{[8]}$ The death rate reflects the number of deaths per 1000 population that would have occurred if people of the same age groups had died at the same rate as the study population over the same time period. The SMR is a ratio of the mortality in the study population (the observed deaths) to that in the general population (the expected deaths) over the same time period.

\section{Statistical analysis}

Continuous variables were expressed as means (standard deviations (SDs)) and categorical data as frequencies and percentages. The overall SMR and SMRs according to age categories of 10 years and to gender were presented accompanied by $95 \%$ confidence intervals (CIs). Comparisons of age at transfer between genders were performed with a Mann-Whitney test. Kaplan-Meier survival curves were plotted, including the number of censored patients at each point, and the median survival rate was calculated. The log-rank test was used to compare median survival rates between gender and transfer destination. Cox proportional hazards regression analysis was used to determine the factors associated with mortality. Independent variables such as age at transfer, gender and transfer destination were included in the model. A p-value of 0.05 was considered significant. The data were analysed with the Statistica package, version 13.2 (Dell Inc., USA).

\section{Ethical considerations}

This study was part of the investigation by the Health Ombud, which was conducted under section $81 \mathrm{~A}(3)$ (b)(ii)v of the National Health Amendment Act No. 12 of 2013. All the data used belong to the Office of the Health Ombud. The data were anonymised, with no links to any patient identifiers, prior to analysis.

\section{Resullts}

Between October 2015 and June 2016, 1442 patients were transferred to alternative care facilities. Men accounted for $73 \%(n=1055)$ of the cohort (Table 1) and were on average younger than the women (mean (SD) 47.0 (12.8) years v. 49.4 (14.3) years; $p=0.004)$.

The transfers were initially conducted in small groups of $10-20$ MHCUs but increased disproportionately in May and June (Table 2). Of the MHCUs, $85 \%(n=1231)$ were placed at either an NGO or the CCRC and $15 \%(n=211)$ at the specialised psychiatric hospitals. Women comprised $<10 \%(n=20)$ of those transferred to the hospitals $(p<0.001)$. No statistically significant differences in age at transfer

Table 1. Cohort of patients transferred between October 2015 and June 2016

\begin{tabular}{|c|c|c|c|}
\hline $\begin{array}{l}\text { Age group } \\
\text { (years) }\end{array}$ & $\begin{array}{l}\text { Men }(N=1055), \\
n(\%)\end{array}$ & $\begin{array}{l}\text { Women }(N=387) \text {, } \\
n(\%)\end{array}$ & $\begin{array}{l}\text { Total }(N=1442) \text {, } \\
n(\%)\end{array}$ \\
\hline $15-19$ & $3(0.3)$ & $1(0.3)$ & $4(0.3)$ \\
\hline $20-24$ & $20(1.9)$ & $10(2.6)$ & $30(2.1)$ \\
\hline $25-29$ & $66(6.3)$ & $23(5.9)$ & $89(6.2)$ \\
\hline $30-34$ & $110(10.4)$ & $28(7.2)$ & $138(9.6)$ \\
\hline $35-39$ & $111(10.5)$ & $40(10.3)$ & $151(10.5)$ \\
\hline $40-44$ & $138(13.1)$ & $42(10.9)$ & $180(12.5)$ \\
\hline $45-49$ & $163(15.4)$ & 49 (12.7) & $212(14.7)$ \\
\hline $50-54$ & $158(15.0)$ & 49 (12.7) & $207(14.3)$ \\
\hline $55-59$ & $112(10.6)$ & $51(13.2)$ & $163(11.3)$ \\
\hline $60-64$ & $71(6.7)$ & $35(9.0)$ & $106(7.3)$ \\
\hline $65-69$ & $43(4.1)$ & $23(5.9)$ & $66(4.6)$ \\
\hline $70-74$ & $24(2.3)$ & $18(4.7)$ & $42(2.9)$ \\
\hline $75-79$ & $15(1.4)$ & $8(2.1)$ & $23(1.6)$ \\
\hline $80-84$ & $8(0.8)$ & $6(1.6)$ & $14(1.0)$ \\
\hline$\geq 85$ & $4(0.4)$ & $3(0.8)$ & $7(0.5)$ \\
\hline Unknown age & $9(0.8)$ & $1(0.3)$ & $10(0.7)$ \\
\hline
\end{tabular}

Table 2. Numbers of people transferred per month and transfer destination

\begin{tabular}{|c|c|c|c|c|c|c|c|c|c|}
\hline & \multicolumn{9}{|c|}{ Month of transfer } \\
\hline & Oct & Nov & Dec & Jan & Feb & Mar & April & May & June \\
\hline & 2015 & 2015 & 2015 & 2016 & 2016 & 2016 & 2016 & 2016 & 2016 \\
\hline Transferred to the CCRC or an NGO & 10 & 11 & 17 & 17 & 17 & 13 & 42 & 713 & 391 \\
\hline Transferred to a psychiatric hospital & 1 & 0 & 0 & 1 & 1 & 1 & 0 & 118 & 89 \\
\hline Total & 11 & 11 & 17 & 18 & 18 & 14 & 42 & 831 & 480 \\
\hline
\end{tabular}


were found between men and women (mean (SD) 54.4 (13.4) years and 58.0 (16.1) years, respectively; $p=0.24$ ).

By the end of August 2017, 9\% ( $n=131)$ of the MHCUs had died (Fig. 1). The 23 months between October 2015 and August 2017 could be divided into three periods. The first, up to the end of August 2016, was prior to public awareness of the mortality. Over half $(n=68)$ of the deaths occurred during this period. Another 40 deaths occurred during the second period, from September 2016 to the end of January 2017. This period may be denoted the 'first rescue intervention', as urgent measures were instigated by the Minister of Health and the Ombud to prevent further unnecessary deaths. During these 5 months, six NGOs were either closed completely or relocated into empty buildings on hospital grounds. Other NGOs were allocated medical and psychiatric assistance mobilised from district and hospital services. The third period, after the release of the Ombud's report, was the 'second rescue intervention', whereby MHCUs were identified and moved under close supervision to safe accommodation. This process was completed by the end of May, after which 7 deaths occurred and 58 MHCUs remained unlocated.

Most deaths $(70 \%, n=92)$ occurred within the first 6 months of the user being transferred, with the first 2 months being the period of highest risk. Of the 131 deaths, 119 (8.3\% of the cohort) occurred within a year of the patient's transfer date.

\section{Survival rates of the cohort}

About $92 \%$ of the men and $89 \%$ of the women survived beyond 400 days of their date of transfer. There was therefore no statistically significant difference between the survival rate of men and that of women (log-rank test, $p=0.106$ ) (Fig. 2). The cumulative survival rate according to transfer destination is shown in Fig. 3. MHCUs transferred to a psychiatric hospital were more likely to survive than those transferred to the CCRC or an NGO (log-rank test, $p=0.00022$ ).

\section{Multivariable hazard Cox proportional regression}

After correcting for gender, we found that for every annual increase in age of the MHCUs, the mortality risk increased by $4.3 \%$ (hazard ratio (HR) $1.043,95 \%$ CI $1.030-1.055 ; p<0.0001$ ). Furthermore, there was a $71.5 \%$ greater probability of survival among those transferred to a psychiatric hospital compared with those transferred to the CCRC or an NGO (HR 0.270, 95\% CI $0.110-0.665 ; p=0.004)$.

\section{Mortality analysis}

The proportion of the total cohort who died during the calendar year of 2016 ( $n=103)$ was compared with the mortality of the general population for 2016 (Table 3). The overall age-adjusted death rate was 63/1 000 population and the overall SMR was 4.9 (95\% CI 3.92 5.80), with an SMR of 3.9 for men (95\% CI 2.95 - 4.86) and 6.3 for women (95\% CI 4.22 - 8.38).

\section{Discussion}

With the data now available, we found an age-adjusted death rate of 63/1 000 among MHCUs transferred from LE to alternative care facilities, almost eight times the preliminary crude death rate of $8 / 1000$ for the general population in 2016. The SMR was significantly high for all age groups except $>80$ years and was considerably higher for women than for men. The only predictors of mortality were increasing age and transfer destination. These two factors could have contributed to the higher SMR among women, as they were older and significantly less likely to be transferred to a specialised hospital.
Discrepancies between our results and figures reported in the media may be noted. These are related to different cut-off dates, and the exclusion of deaths caused by the transfer of MHCUs out of the CCRC or NGOs to create space for those transferred from LE from this study.

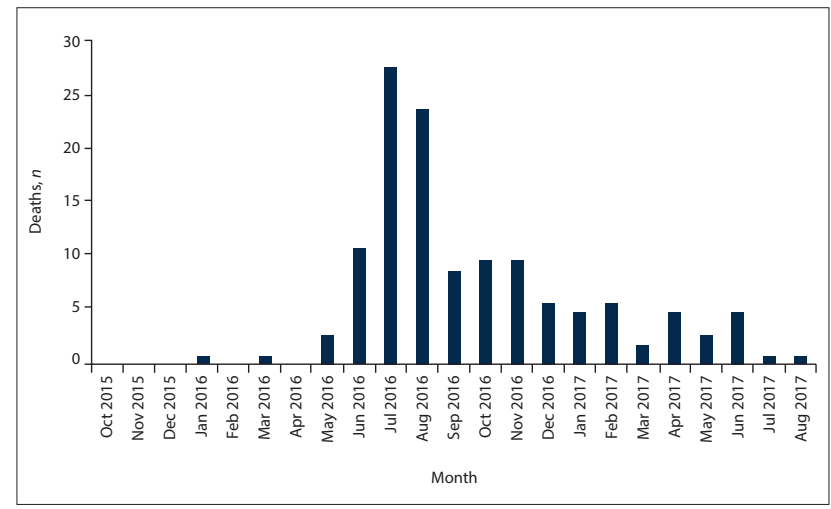

Fig. 1. Numbers of deaths as they occurred between October 2015 and August 2017 (N=131).

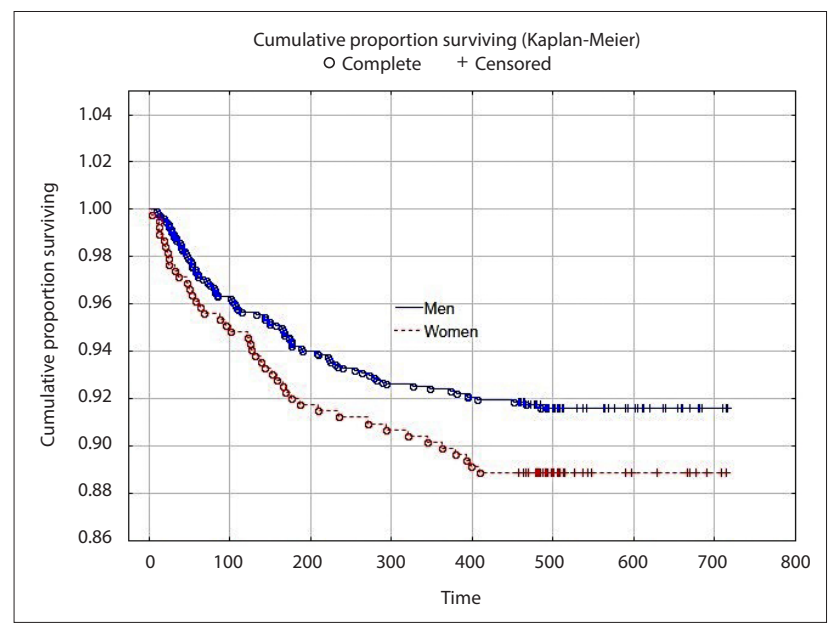

Fig. 2. Cumulative survival rate from date of transfer: men v. women (logrank test, $\mathrm{p}=0.106)$.

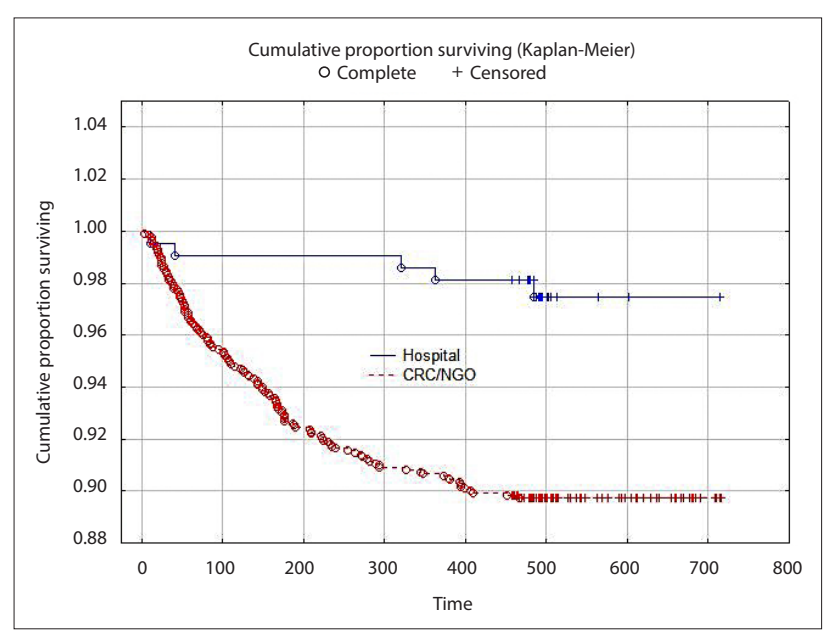

Fig. 3. Cumulative survival rate from date of transfer: psychiatric hospital v. the CCRC and NGOs (log-rank test, $\mathrm{p}=0.00022) .(C C R C=$ Cullinan Care and Rehabilitation Centre; NGOs = non-governmental organisations.) 
Table 3. Age-adjusted death rate and SMR for deaths in 2016

\begin{tabular}{|c|c|c|c|c|c|c|}
\hline \multirow[b]{2}{*}{ Age group } & \multicolumn{3}{|c|}{ Deaths in $2016, n$} & \multirow{2}{*}{$\begin{array}{l}\text { Death rate per } 1000 \\
\text { population }\end{array}$} & \multirow[b]{2}{*}{ SMR } & \multirow[b]{2}{*}{$95 \% \mathrm{CI}$} \\
\hline & $\operatorname{Men}(N=68)$ & Women $(N=35)$ & Total $(N=103)$ & & & \\
\hline$\leq 19$ & - & - & - & - & - & - \\
\hline $20-29$ & 3 & 2 & 5 & 42 & 11.3 & $1.34-21.26$ \\
\hline $30-39$ & 7 & 1 & 8 & 28 & 3.8 & $1.15-6.45$ \\
\hline $40-49$ & 16 & 7 & 23 & 59 & 5.8 & $3.45-8.15$ \\
\hline $50-59$ & 16 & 10 & 26 & 70 & 4.6 & $2.84-6.36$ \\
\hline $60-69$ & 18 & 6 & 24 & 139 & 5.8 & $3.47-8.13$ \\
\hline $70-79$ & 6 & 6 & 12 & 185 & 4.4 & $1.91-6.89$ \\
\hline$\geq 80$ & 2 & 3 & 5 & 238 & 2.3 & $0.32-4.28$ \\
\hline
\end{tabular}

\section{Mortality in people with mentall illness} Although the burden of disease due to mental illness is most commonly due to disability, mortality rates are known to be higher among the mentally ill than the general population. ${ }^{[1]}$ In their metaanalysis of $>200$ studies from 29 countries and 6 continents, Walker et al. ${ }^{[1]}$ calculated the pooled relative risk of all-cause mortality to be 2.2 times greater among people with mental illness than the general population, with over two-thirds of deaths due to natural causes and a median reduced life expectancy of 10 years.

Two African studies not included in the meta-analysis are a community-based prospective cohort study in Ethiopia by Fekadu et al. ${ }^{[9]}$ and a South African (SA) retrospective review of psychiatric hospital inpatients by Khamker et al. ${ }^{[10]}$ After following up $>900$ patients for 10 years, Fekadu et al. ${ }^{[9]}$ found a mortality rate double that of the general population; $13.2 \%$ of the cohort died, almost half from infectious diseases and a quarter from unnatural causes. Significant predictors of mortality were male gender and spending $<50 \%$ of time in symptom remission from the psychiatric illness. In contrast to the overall global risk of mortality, Khamker et al. ${ }^{[10]}$ found a mortality rate equivalent to that of the general population among specialised psychiatric hospital inpatients.

The significantly higher survival rate conferred by transfer to a specialised hospital in the LE cohort is consistent with the findings of Khamker et al., ${ }^{[10]}$ whose study was conducted in one of the same hospitals. The significance of transfer destination for survival implies that inadequate care for the frailty of the MHCUs at the CCRC and NGOs was the main cause of the high mortality in our cohort. Although we did not have clinical diagnoses, the examination of 38 patient deaths during the initial investigation revealed the MHCUs to be low functioning, with intellectual disability, epilepsy and dementia as frequent diagnoses as well as schizophrenia and bipolar disorder.

\section{International studies of mortality associated with deinstitutionalisation}

International observational studies of the deinstitutionalisation process during the 1980s and 1990s revealed a significantly high SMR among psychiatric patients in the initial years after hospital discharge. ${ }^{[11-14]}$ In Italy, Meloni et al. ${ }^{[11]}$ found an overall SMR of 4.0 for natural deaths and an SMR of 30.4 for unnatural deaths in the first year after discharge from a long-stay hospital. In Finland, Sohlman and Lehtinen $^{[12]}$ followed up 22940 patients discharged from psychiatric hospitals in 1988. Of their cohort, 3.7\% died within the first year, equating to an SMR of 7.9 for men and 5.3 for women. Their very high SMR reflects the younger age at death of the discharged patients compared with the longer life expectancy of the general population. Suicide was the single most common cause of death and accounted for $50 \%$ of deaths among patients aged $<30$ years.
The international experience differs from the Life Esidimeni tragedy in that the discharges were planned, patient details were documented, there were no 'rescue interventions', and a significant proportion of deaths were from suicide or trauma. In general, their cohorts comprised almost equal numbers of men and women and a higher mortality rate among men. Nevertheless, a common conclusion of the international studies relevant to SA is that this is a vulnerable patient population: continuity of care and community-based mental health services are essential.

\section{Costs of care and deinstitutionalisation}

The termination of the contract between the GDoH and LE was done in the interests of affordability and the need to re-prioritise the budget. Using the 2016 costs detailed in the Ombud's report, the daily cost per MHCU at the NGOs was approximately a third of that at LE and less than a twelfth of specialised hospital care. However, any planned cost savings did not materialise, as the cost of the 211 patients transferred to the specialist psychiatric hospitals was about $80 \%$ of the entire cohort in the medium-care setting of LE. In addition, the inability of the CCRC and NGOs to provide adequate care resulted in the rehospitalisation of MHCUs who experienced a relapse of illness, and eventual transfer of almost all the initial cohort back into long-stay hospital care.

This experience is consistent with the findings of Knapp et al. ${ }^{[15]}$ in their economic evaluation of deinstitutionalisation in Europe. They caution against the perception that community care will cost less than hospital-based care, particularly for people with severe mental disability. In addition, community-based costs may be more difficult to anticipate or measure as they are borne by multiple stakeholders. The advantage of community-based care is that it is more cost-effective in achieving broader patient coverage and improved functioning. However, it needs thorough planning with flexible budgeting. Agreement by all stakeholders is required prior to the transfer of the patient. Planning should consider the intensity of care required during the transition, the needs of the patient once in the community, and the desired long-term outcomes.

A further explanation provided by the $\mathrm{GDoH}$ for the decision to transfer MHCUs from hospital to NGOs was that it was in line with the 2002 MHCA. In SA, deinstitutionalisation began in the $1990 \mathrm{~s}^{[16]}$ and escalated after the MHCA enshrined the right for MHCUs to be cared for in the least restrictive environment and to receive mental healthcare close to their homes. ${ }^{[6]}$ In Gauteng, long-stay beds were reduced from 70/100 000 population in 1994 to 35/100 000 in 2004, and continued to be cut until 2008, after which repeated readmissions prevented further planned reductions. ${ }^{[17]}$ Although there was an initial expansion of community mental health services in the late 1990 s, this was not sustained. ${ }^{[18]}$ 
While it is indisputable that the CCRC and NGOs were not equipped for the level of care required in the Life Esidimeni tragedy, the degree of preventable mortality that occurs among MHCUs under 'usual care' is unknown. In addition, an affordable and effective means of community-based care for the severely mentally ill needs to be ascertained. Nevertheless, the provision of appropriate mental healthcare aligned to the human rights-based SA Constitution of 1996 and related health legislation remains. ${ }^{[7,19,20]}$

\section{Study limitations}

This study formed part of the Ombud's investigation of the Life Esidimeni tragedy. It is limited by the quality of the available data, which were compiled retrospectively from multiple sources.

\section{Conclusion}

Notwithstanding the limitations, this study provides quantitative evidence of an excessively high mortality among the MHCUs transferred from LE to the CCRC and NGOs. The data confirm the sentiments of the general public when the deaths first became known, the findings of the initial investigation, and the extreme vulnerability of this patient population.

Acknowledgements. This study was conducted as part of the investigation by the Office of the Health Ombud and required no funding. It was made possible only by the extensive effort of the data verification team, the contribution of Dr Pali Lehohla, former Statistician-General, and expert assistance and advice provided by Prof. Elena Libhaber, biostatistician at the University of the Witwatersrand's Faculty of Health Sciences.

Author contributions. The authors contributed equally to the study design and interpretation. LJR searched the background literature and wrote the manuscript under the guidance of MWM.

Funding. None.

Conflicts of interest. None.

1. Walker ER, McGee RE, Druss BG. Mortality in mental disorders and global disease burde implications: A systematic review and meta-analysis. JAMA Psychiatry 2015;72(4):334-341. https:// doi.org/10.1001/jamapsychiatry.2014.2502
2. Makgoba MW. The report into the 'Circumstances surrounding the deaths of mentally ill patients: Gauteng Province'. South Africa: Office of the Health Ombud, 2017. http://healthombud.org.za/ report-into-the-circumstances-surrounding-the-deaths-of-mentally-ill-patients-gauteng-province (accessed 30 August 2018).

3. News 24. Life Esidimeni. https://www.news24.com/Tags/Topics/life_esidimeni (accessed 19 February 2018).

4. Capri C, Watermeyer J, Mckenzie J, Coetzee O. Intellectual disability in the Esidimeni tragedy: Silent deaths. S Afr Med J 2018;108(3):153-154. https://doi.org/10.7196/SAMJ.2017.v108i3.13029

5. Ferlito BA, Dhai A. The Life Esidimeni tragedy: The courts are also to blame. S Afr Med 2018;108(3):155-156. https://doi.org/10.7196/SAMI.2017.v108i3.13011

6. Gauteng Department of Health. South Africa: Gauteng Health terminates Life Healthcare Esidimen Gauteng Department of Health. South Africa: Gauteng Health terminates Life Healthcare Esidimeni
contract. Press release 21 October 2015. https://www.gov.za/speeches/gauteng-health-terminateslife-healthcare-esidimeni-contract-21-oct-2015-0000 (accessed 11 February 2018).

7. South Africa. Mental Health Care Act No.17 of 2002. http://www.hpcsa.co.za/Legislation (accessed 5 September 2018)

8. Naing NN. Easy way to learn standardization: Direct and indirect methods. Malays J Med Sci 2000;7(1):10-15. https://www.ncbi.nlm.nih.gov/pubmed/22844209 (accessed 5 September 2018).

9. Fekadu A, Medhin G, Kebede D, et al. Excess mortality in severe mental illness: 10-year populationbased cohort study in rural Ethiopia. Br J Psychiatry 2015;206(4):289-296. https://doi.org/10.1192/ bip.bp. 114.149112

10. Khamker N, Moola NM, Roos JL, Rheeder P. Profile of mortality of patients admitted to Weskoppies Psychiatric Hospital in South Africa over a 5-year period (2001 - 2005). Afr J Psychiatry 2010;13(3):211-217. https://www.ncbi.nlm.nih.gov/pubmed/20957320

1. Meloni D, Miccinesi G, Bencini A, et al. Mortality among discharged psychiatric patients in Florence, Italy. Psychiatr Serv 2006;57(10):1474-1481. https://doi.org/10.1176/ps.2006.57.10.1474

12. Sohlman B, Lehtinen V. Mortality among discharged psychiatric patients in Finland. Acta Psychiat Scand 1999;99(2):102-109. https://doi.org/10.1111/j.1600-0447.1999.tb07207.x

13. Hansen V, Jacobsen BK, Arnesen E. Cause-specific mortality in psychiatric patients after deinstrion

Hoang U, Stewart R, Goldacre MJ. Mortality after hospital discharge for people with schizophrenia Hoang U, Stewart R, Goldacre MJ. Mortality after hospital discharge for people with schizophrenia
or bipolar disorder: Retrospective study of linked English hospital episode statistics, $1999-2006$. BMJ 2011;343:d5422. https://doi.org/10.1136/bmj.d5422

15. Knapp M, Beecham J, McDaid D, Matosevic T, Smith M. The economic consequences of deinstitutionalisation of mental health services: Lessons from a systematic review of European experience. Health Soc Care Community 2011;19(2):113-125. https://doi.org/10.1111/j.13652524.2010.00969.x

16. Lazarus R. Managing de-institutionalisation in a context of change: The case of Gauteng, South Africa. S Afr Psychiatry Rev 2005;8(2):65-69. https://www.ajol.info/index.php/ajpsy/article/ view/30186/22805 (accessed 5 September 2018).

17. Office of the Health Ombud. Expert Panel Report for Health Ombudsperson on the investigation around the circumstances of deaths of patients at NGOs 2017. www.healthombud.org.za (accessed 19 February 2018).

18. Robertson LJ, Szabo CP. Community mental health services in Southern Gauteng: An audit using District Health Information Systems data. S Afr J Psychiatry 2017;23(0):a1055. https://doi. org/10.4102/sajpsychiatry.v23i0.1055 (accessed 5 September 2018).

19. Statutes of the Republic of South Africa - Constitutional Law. Constitution of the Republic of South Africa No. 108 of 1996. https://www.gov.za/documents/constitution-republic-south-africa-1996 (accessed 5 September 2018)

20. South Africa. National Health Act 61 of 2003. http://www.hpcsa.co.za/Legislation (accessed 5 September 2018)

Accepted 5 April 2018 